\title{
Spectrophotometric Determination of Trace Amounts of Eosin B Dye after Cloud Point Extraction
}

\author{
ARDESHIR SHOKROLLAH ${ }^{1 *}$ and ZAHRA MALEKHOSSEINI ${ }^{1,2}$ \\ ${ }^{1}$ Department of Chemistry, Yasouj University, Yasouj, 75918-74831, Iran \\ ${ }^{2}$ Young Researchers Clubs, Yasouj Branch, Islamic Azad University, Yasouj, Iran \\ ashokrollahi@mail.yu.ac.ir
}

Received 1 April 2013 / Accepted 30 April 2013

\begin{abstract}
Cloud point extraction (CPE) was carried out to extract Eosin B dye from aqueous solution using non-ionic surfactant Triton X-114. The enrichment of dye was determined by a spectrophotometric study. The effects of different operating parameters, e.g., concentrations of surfactant, salt, temperature, $\mathrm{pH}$, the heating time, equilibration temperature and time of centrifuge have been studied. The extracted surfactant-rich phase was diluted with ethanol and its absorbance was measured at $533 \mathrm{~nm}$. The calibration curve was linear in the range of $0.0067-0.7300 \mathrm{mgL}^{-1}$ with $\mathrm{r}^{2}=0.995$. The detection limit, preconcentration and enrichment factor were obtained $1.08 \mathrm{ng} \mathrm{mL}^{-1}, 15.00$ and 11.20, respectively. The effect of some foreign species including cations, anions and similar dye, fluorescein was also investigated. This method was applied successfully for determination of the amount of Eosin B in water samples.
\end{abstract}

Keywords: Eosin B, Cloud point, Triton x-114, Spectrophotometric study

\section{Introduction}

Commercially, there are more than 100,000 dyes with over $7 \times 10^{5}$ tons of dyestuffs produced yearly. Synthetic dyes are used in the textile, leather, paper, rubber, plastics, cosmetics, pharmaceuticals and food industries. Generally, synthetic dyes have complex aromatic structures that make them stable and difficult to biodegrade ${ }^{1}$. Dyes even in low concentrations affect the aquatic life and food $\mathrm{web}^{2}$.

Eosin B (Figure 1) is a novel antimalaria agent for drug-resistant plasmodium falciparum; therefore, its determination is very important ${ }^{3}$.Thus, due to the useful effects of Eosin B, it was considered worthwhile to make efforts to develop a simple method to determine Eosin B in water samples. Applications of Eosin B are in a sequential injection method to determine tween-80 in natural water samples ${ }^{4}$ and to determine dye binding s mechanism in the protein assay ${ }^{5}$.

Cloud point extraction (CPE) by phases of nonionic surfactants (NS) is a selective and a friendly biological-environmental method for separation and preconcentration ${ }^{6-8}$. CPE method has been successfully employed for the preconcentration of metal ions ${ }^{9-12}$ and organic compounds such as polycyclic aromatic hydrocarbons ${ }^{13-15}$, polychlorinated compounds $^{16}$, vitamins ${ }^{17-19}$, dyes ${ }^{20-22}$ and biomaterials ${ }^{23}$. 
<smiles>O=C(O)c1ccccc1-c1c2cc([N+](=O)[O-])c(=O)c(Br)c-2oc2c(Br)c(O)c([N+](=O)[O-])cc12</smiles>

Figure 1. Chemical structure of Eosin B

CPE method can be easily combined with several analytical methods such as spectral ${ }^{24-26}$, inductively coupled plasma (ICP) ${ }^{27}$, atomic absorption ${ }^{28,29}$, chromatographic ${ }^{30,31}$, flow injection $^{32}$. Also, the auxiliary techniques was coupled with this method, some of these are: ultrasonic-assisted cloud point extraction (UA-CPE) ${ }^{33}$, microwave-assisted cloud point extraction (MA-CPE) $)^{34}$, stirring-assisted cloud point extraction (SA-CPE) ${ }^{35}$ and solvent floatation spectrophotometry ${ }^{36}$. Recently a new method for monitoring of signal after cloud point extraction (CPE) of dyes was introduced by our group researcher ${ }^{37}$. Therefore, extraction with NS phases could be coupled with highly sensitive and convenient analytical methods. In the present study, a simple and sensitive CPE procedure has beendeveloped for extraction and preconcentration of Eosin B using Triton X-114 as nonionic surfactant by spectrophotometric method.

\section{Experimental}

All chemicals used were of analytical grade and double distilled water was used throughout. A $1 \%(w / v)$ Triton X-114 (Fluka, Buchs, Switzerland) solution was prepared by dissolving $1.0 \mathrm{~g}$ of Triton X-114 in $100 \mathrm{~mL}$ volumetric flask with stirring. All the used dyes were purchased from Merck (E. Merck, Darmstadt, Germany). A stock solution of $100 \mathrm{mgL}^{-1}$ of Eosin B was prepared by dissolving $0.0100 \mathrm{~g}$ of Eosin $\mathrm{B}$ in water and diluting to $100 \mathrm{~mL}$ in a volumetric flask. All the other chemicals used were analytical grade of Merck (Darmstadt, Germany).

\section{Instrumentation}

A Jasco V-530, UV-Visible spectrophotometer (Hachioji, Tokiyo,Japan was used for recording absorption spectra and absorbance measurements using $1 \mathrm{~cm}$ glass cells. A Metrohm (Herisau, Switzerland) digital pH-meter model 827 with combined glass electrode was used for $\mathrm{pH}$ adjustments. A F.A.G thermostat bath (Iran) was used for the temperature adjustment. Also, a centrifuge with $15.0 \mathrm{~mL}$ calibrated tubes (RHB, Iran) was used to accelerate the phase separation process.

\section{Test procedure}

A typical cloud point experiment has been carried out according to following procedure. An aliquot of $15 \mathrm{~mL}$ of an aqueous solution containing $0.27 \mathrm{mgL}^{-1}$ of Eosin B, $0.13 \%(\mathrm{w} / \mathrm{v})$ of Triton $\mathrm{x}-114 \mathrm{in} \mathrm{pH} 3.5$ was prepared. The mixture was left to stand for $5 \mathrm{~min}$ in a thermostat bath at $28{ }^{\circ} \mathrm{C}$. Separation of the phases was achieved by centrifugation for $10 \mathrm{~min}$. The whole system was cooled in an ice and salt bath so that the surfactant rich phase would regain its viscosity and the bulk aqueous phase was easily decanted. The surfactant rich phase was diluted with ethanol to $1.0 \mathrm{~mL}$. The absorption spectrum of Eosin B was recorded after cloud point extraction. It showed a maximum absorption band at $533 \mathrm{~nm}$ (Figure 2). Therefore, this wavelength was used for all the absorbance measurements. To obtain calibration curves, absorbance values were plotted vs. analyte concentrations. 


\section{Results and Discussion}

A cloud point extraction methodology was developed to determine precocentration and spectrophotometric of Eosin B. The absorption spectrum of Eosin B was recorded after cloud point extraction with Triton X-114. As it is obvious from Figure 2, the absorption after cloud point extraction was increased considerably. The effect of various cloud point extraction parameters such as $\mathrm{pH}$, Triton $\mathrm{x}-114$ and electrolyte concentration, time of centrifugation, equilibration temperature and time on the performance of the method was investigated in order to achieve highest sensitivity.

\section{Effect of $\mathrm{pH}$}

For organic molecules, $\mathrm{pH}$ is perhaps the most critical factor regulating the partitioning of the target analyte in the micellar phase. Especially for ionizable species, maximum extraction efficiency is achieved at $\mathrm{pH}$ values where the uncharged form of the target analyte prevails. The ionic form of analytes does not interact with the micellar aggregate as strongly as its neutral form does.

The effect of $\mathrm{pH}$ on the cloud point extraction of $0.27 \mathrm{mg} \mathrm{L}^{-1}$ of Eosin B was studied in the range of 1-8 by adding hydrochloric acid and sodium hydroxide. Figure 3 shows that at $\mathrm{pH} 3.5$, maximum color intensity can be obtained. The existence of $\mathrm{COOH}$ group in the structure of Eosin B causes neutral form to be obtained in low PHS and this subject helpsdye to transfer to surfactant phase. In extremely acidic $\mathrm{pH}$, neutral dye molecule will become cationic via accepting $\mathrm{H}^{+}$ion and therefore recovery will be reduced. In higher $\mathrm{pH}$, especially in alkaline solution the anionic form is mostly present and this leads to the reduction of the extraction efficiency.

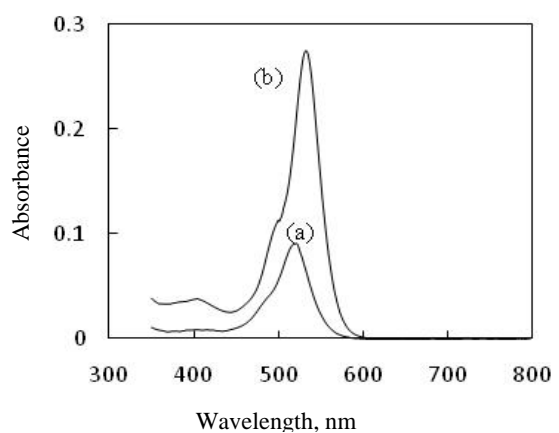

Figure 2. The absorption spectrum of (a) 5 ppm of Eosin B in distillated water without cloud point extraction (b) 0.27 ppm Eosin B in ethanol after cloud point extraction

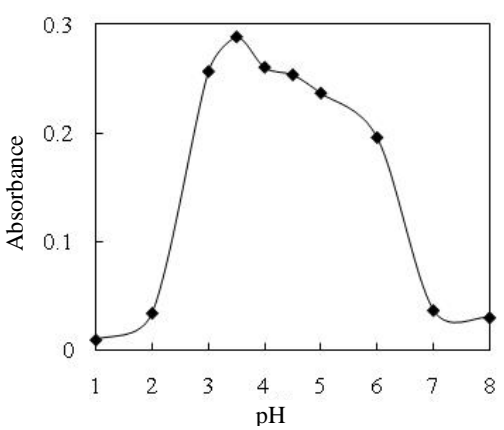

Figure 3. Effect of $\mathrm{pH}$ on the $\mathrm{CPE}$ of Eosin B

\section{Effect of triton $x-114$ concentration}

For a successful cloud point extraction, it is desirable to obtain minimum amount of surfactant for maximum extraction of dye. Therefore, the effect of the surfactant concentration was investigated in order to ensure maximum extraction efficiency. The preconcentration efficiency was evaluated using Triton $\mathrm{x}-114$ concentrations ranging from $0.03 \%$ to $0.4 \%(\mathrm{w} / \mathrm{v})$. The results are demonstrated in Figure 4 . The highest signal was obtained with $0.13 \%(\mathrm{w} / \mathrm{v})$ Triton $\mathrm{x}-114$. The efficiency of extraction was increased by increasing the surfactant concentration to $0.13 \%(\mathrm{w} / \mathrm{v})$. At lower surfactant concentrations, 
the recovery is reduced because of the incomplete recovery of the extraction. The decreased signal at concentrations higher than $0.13 \%(w / v)$ is due to remaining of some Triton X-114 and analyte in the aqueous solution phase. Therefore, this phase can compete with the surfactant-rich phase to draw analyte into itself. Also, at a high concentration of surfactant, the viscosity of the enrichment phase was increased and the signal was decreased.

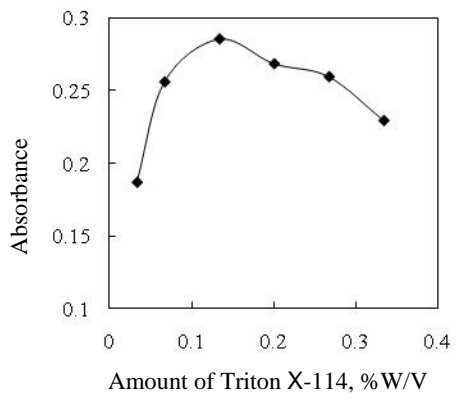

Figure 4. Effect of Triton $\mathrm{X}-114$ concentration on the CPE of Eosin B

\section{Effects of equilibration temperature and time}

Optimal equilibration temperature and time are necessary to achieve easy phase separation and efficient preconcentration. If the temperature is lower than the cloud point (CP) temperature, two phases cannot be formed. But higher temperature leads to dissociation of surfactant-dye assembly and too high temperature may lead to the decomposition of analyte. Therefore, the effect of equilibration temperature in the range of $25-50{ }^{\circ} \mathrm{C}$ was studied. It was found that the extraction efficiency reaches maximum in $28^{\circ} \mathrm{C}$. So, an equilibration temperature of $28^{\circ} \mathrm{C}$ was chosen for the analysis.

The dependence of extraction efficiency upon equilibration time was also studied for a time interval of 5-30 min., maximum extraction efficiency was observed in $5 \mathrm{~min}$. Therefore, an incubation time of 5 min was chosen to be used in the next experiments.

\section{Effect of centrifuge time}

For obtaining the best efficiency of the method, it is required to preconcetrate trace amount of dye with high sensitivity and in a short time. Optimum time in the centrifugation is one of the parameters in the CPE procedure.As it is obvious from Figure 5 the time of centrifugation in range of 5-30 was investigated.This Figure shows that the best separation was obtained with centrifugation time of 10 min.at shorter times the separation was not complete and it is probably the longer centrifugation time that caused the partial back extraction into the aqueous phase.

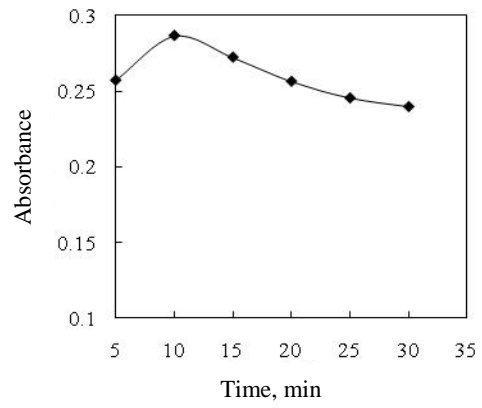

Figure 5. Effect of time of centrifuge on the CPE of Eosin B 


\section{Effect of electrolytes}

The cloud point of micellar solutions can be controlled by adding salts, alcohols, non-ionic surfactants and some organic compounds (salting-out effects). In order to study the effect of the addition of electrolytes on micellar solutions of Eosin $\mathrm{B}, \mathrm{KNO}_{3}$ solution was tested. It was observed that the addition of $\mathrm{KNO}_{3}$ within the interval of $0.0067-0.47 \mathrm{mg} \mathrm{L}^{-1}$ had no significant effect on the cloud point extraction efficiency.

\section{Interference studies}

The influences of some diverse anions, cations and fluorescein as similar dye usually present in natural waters and wastewater on the determination of Eosin B were studied.Various amounts of other species were added to a solution containing $0.27 \mathrm{mgL}^{-1}$ of Eosin $\mathrm{B}$ and the recommended procedure under optimum conditions was applied. An error of $5 \%$ in the absorbance reading was considered tolerable value. The results presented in Table 1 show the good selectivity of the procedure.

Table 1. The effect of ions and fluorescein dye on the determination of $0.27 \mathrm{mgL}^{-1}$ of Eosin B

\begin{tabular}{cc}
\hline Tolerance ratio(w/w) & Foreign ions \\
\hline 1 & Fluorescein \\
500 & $\mathrm{Cu}^{2+}, \mathrm{Ni}^{2+}, \mathrm{Mg}^{2+}, \mathrm{Tl}^{+}, \mathrm{Zn}^{2+}$ \\
1000 & $\mathrm{Cr}^{3+}, \mathrm{Co}^{2+}$ \\
1000 & $\mathrm{NO}_{3}^{-}, \mathrm{Cl}^{-}$ \\
\hline
\end{tabular}

\section{Analytical performance}

The calibration graph was linear in the range of $0.0067-0.73 \mathrm{mgL}^{-1}$ of Eosin B in the initial solution by applying the optimized conditions. The results are demonstrated in Figure 6. The equation for the line was $A=0.889 C+0.004$ with regression coefficient $\left(r^{2}\right)$ of $0.995(n=10)$ where $\mathrm{A}$ is the absorbance and $\mathrm{C}$ is the concentration of Eosin $\mathrm{B}$ in $\mathrm{mg} \mathrm{L}^{-1}$.detection limit based on three times the standard deviation of the blank $\left(3 \mathrm{~S}_{\mathrm{b}}\right)$ was $1.08 \mathrm{ngmL}^{-1}$ and the relative standard deviation (RSD) for $0.27 \mathrm{mgL}^{-1}$ of Eosin $\mathrm{B}(\mathrm{n}=8)$ was $3.12 \%$.The enrichment factor defined as the ratio of the slopes of calibration curve before and after preconcetration was 11.20. The preconcetration factor based on the ratio of initial volume in centrifuge tube to final volume of dissolving solvent was obtained 15.00 (Table 2).

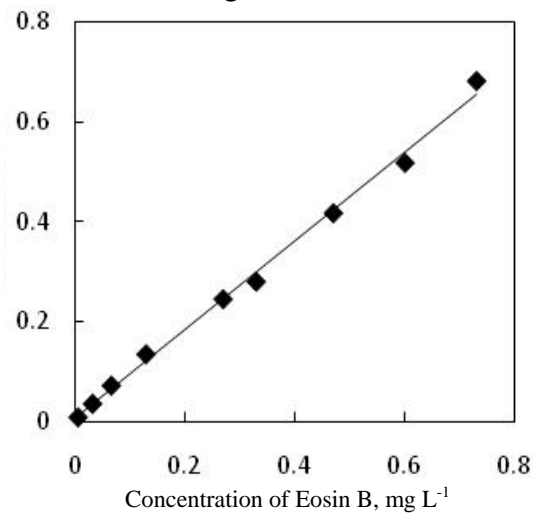

Figure 6. Calibration graph of Eosin B in CPE 
Table 2. Analytical characteristics

\begin{tabular}{ll}
\hline \multicolumn{1}{c}{ Analytical Performance Characteristics } & \multicolumn{1}{c}{ Data } \\
\hline Linear equation(n=10) & $\mathrm{A}=0.889 \mathrm{C}+0.004$ \\
Range of concentration, mg/L & $0.0067-0.7300$ \\
Regression coefficient $\left(\mathrm{r}^{2}\right)$ & 0.995 \\
Detection limit, ng/L & 1.08 \\
Preconcentration Factor & 15.00 \\
Enrichment Factor & 11.20 \\
\% Relative standard deviation(R.S.D) & 3.12 \\
\hline
\end{tabular}

\section{Application to water samples}

In order to test the reliability of the proposed methodology for the assay of Eosin B, it was applied to the determination of concentration this dye in water samples including tap, Damavand mineral and Bashar River (in the Yasouj city) under optimum conditions. Since an official or standard method does not exist for the determination of Eosin B, the developed methodology was validated by recovery studies. Good recoveries (92.48-100.00\%) were achieved for all analyzed samples (Table 3).

Table 3. Determination of Eosin B in mineral water, tap water and river water

\begin{tabular}{ccccccc}
\hline Sample & Slope & Intercept & $\begin{array}{c}\text { Regression } \\
\text { coefficient }\end{array}$ & $\begin{array}{c}\text { Added } \\
\text { concentration } \\
\mathrm{mg} \mathrm{L}^{-1}\end{array}$ & $\begin{array}{c}\text { Eosin B } \\
\text { found } \\
\mathrm{mg} / \mathrm{L}\end{array}$ & $\begin{array}{c}\text { Recovery } \\
\%\end{array}$ \\
\hline Tap water & & & & 0 & $\mathrm{Nd}^{\mathrm{a}}$ & --- \\
& \multirow{2}{*}{1.29} & -0.009 & 0.993 & 0.133 & 0.133 & 100.00 \\
& & & & 0.270 & 0.265 & 98.14 \\
\hline $\begin{array}{c}\text { Mineral } \\
\text { water }\end{array}$ & \multirow{2}{*}{1.05} & \multirow{2}{*}{0.019} & \multirow{2}{*}{0.992} & 0.133 & 0.133 & 100.00 \\
& & & & 0.270 & 0.263 & 97.41 \\
\hline River & \multirow{2}{*}{1.22} & -0.007 & \multirow{2}{*}{0.996} & 0.133 & 0.123 & 92.48 \\
water & & & & 0.270 & 0.270 & 100.00 \\
\hline
\end{tabular}

${ }^{a}$ Not detected

\section{Conclusion}

In this paper, we introduced a novel and sensitive cloud point extraction procedure as a rapid, safe and inexpensive method for the extraction, preconcentration, and determination of Eosin B spectrophotometrically. The method validation yielded good results and included linearity, repeatability/ reproducibility, sensitivity, recovery and accuracy. The proposed method can be applied to the determination of Eosin B in presence of its family dyes such as fluorescein and water samples.

\section{Acknowledgement}

The financial support of this work by Yasouj University is greatly acknowledged. 


\section{References}

1. Hsiu-Mei C, Ting-Chien C, San-Dec P and Hung-Lungd C, J Hazard Mater., 2009, 161(2-3), 1384-1390; DOI:10.1016/j.jhazmat.2008.04.102

2. Shokrollahi A, Alizadeh A, Malekhosseini Z and Ranjbar M, J Chem Eng Data, 2011, 56(10), 3738-3746; DOI:10.1021/je200311y

3. Massimine M K, Mcintosh M T, Doan L T, Atreya C E, Gromer S, Sirawaraporn W, Elliott A D, Joiner A K, Heiner Schirmer R and Anderson S K, Antimicro Agents Chemother., 2006, 50(9), 3132-3141; DOI:10.1128/AAC.00621-06

4. Salma M Z Al-Kindy, Fakhreldin O Suliman, Salama B Salama, Mohamed Aoudia, Seif N Al-Bahry and Hamoud S Al-Bahlany, Anal Sci., 2003, 19(5), 737-742; DOI:10.2116/analsci.19.737

5. $\quad$ Waheed A A, Sridhar Rao K and Gupta P D, Anal Biochem., 2000, 287(1),73-79; DOI: 10.1016/abio.2000.4793

6. Pramauro E and Pelezetti E, Surfactants in Analytical Chemistry, Elsevier, Amsterda, 1996.

7. Bi W, Tian M and Row K H, Food Chem., 2011, 126(4), 1985-1990;

DOI:10.1016/j.foodchem.2010.12.059

8. Manzoori J L and Karim-Nezhad G, Anal Chim Acta, 2003, 484(2), 155-161; DOI:10.1016/S0003-2670(03)00343-X

9. Ghaedi M, Shokrollahi A, Niknam K, Niknam E and Soylak M, Cent Eur J Chem., 2009, 7(1), 148-154; DOI:10.2478/s11532-008-0102-8

10. Ghaedi M, Shokrollahi A, Mehrnosh R, Hosaini O and Soylak M, Cent Eur J Chem., 2008, 6(3), 488-496; DOI:10.2478/s11532-008-0049-9

11. Ghaedi M, Shokrollahi A, Fathi M R, Gharaghani S and Soylak M, Quim Nova., 2008, 31, 70; DOI:10.1590/S0100-40422008000100015

12. Soylak M, Kaya B and Tuzen M, J Haz Mater., 2007, 147(3), 832-837; DOI:10.1016/j.jhazmat.2007.01.082

13. Yao B and Yang L, J Colloid Interface Sci., 2008, 319(1), 316-321; DOI:10.1016/j.jcis.2007.11.033

14. Li C F, Wong J W C, Huie C W and Choi M M F, J Chromatogr., 2008, 1214, 11-16; DOI:10.1016/j.chroma.2008.10.062

15. Ferrer R, Beltran J L and Guiteras J, Anal Chim Acta., 1996, 330(2-3), 199-206; DOI:10.1016/0003-2670(96)00176-6

16. Eiguren-Fernandez A, Sosa-Ferrera Z and Santana-Rod-Riguez J J, Anal Chim Acta, 1998, 358(2), 145-155; DOI:10.1016/S0003-2670(97)00618-1

17. Tabrizi A B, Bull Korean Chem Soc., 2006, 27, 1604-1608.

18. Ortega A C, Silva D C, Visentainer J V, de Souza N E, Almeida V C and Oliveira C C, Anal Lett., 2011, 44(5), 778-786; DOI:10.1080/00032711003783184

19. Abdollahi H and Bagheri L, Anal Chim Acta, 2004, 514(2), 211-218; DOI:10.1016/j.aca.2004.03.048

20. Liu W, Zhao W, Chen J and Yang M, Anal Chim Acta, 2007, 605(1), 41-45; DOI:10.1016/j.aca.2007.10.034

21. Alam M S and Kabir-ud-Din, Colloid Surface B., 2008, 65(1), 74-79; DOI: 10.1016/j.colsurfb.2008.02.021

22. Purkait M K, Banerjee S, Mewara S, DasGupta S and De S, Water Res., 2005, 39(16), 3885-3890; DOI:10.1016/j.watres.2005.07.034 
23. Lopes A S, Garcia J S, Catharino R R, Santos L S, Eberlin M N and Arruda M A Z, Anal Chim Acta, 2007, 590, 166-172.

24. Pourreza N, Rastegarzadeh S and Larki A, Food Chem., 2011, 126(3), 1465-1469; DOI:10.1016/j.foodchem.2010.11.158

25. Bingjia Y, Li Y, Qiong H and Akita S, Chin J Chem Eng., 2007, 15(4), 468-473; DOI:10.1016/S1004-9541(07)60110-4

26. Wen X, Wu P, Chen L and Hou X, Anal Chim Acta, 2009, 650(1), 33-38; DOI:10.1016/j.aca.2009.01.053

27. Li Y and Hu B, Spectrochim Acta, 2007, 62(10), 1153-1160;

DOI: 10.1016/j.sab.2007.07.005

28. Shokrollahi A, Ghaedi M, Hossaini O, Khanjari N and Soylak M, J Hazard Mater., 2008, 160(2-3), 435-440; DOI:10.1016/j.jhazmat.2008.03.016

29. Jiang X, Wen S, and Xiang G, J Hazard Mater., 2010, 175(1-3), 146-150; DOI:10.1016/j.jhazmat.2009.09.141

30. Ling W, Gui-bin J, Ya-qi C, Bin H, Ya-wei W and Da-zhong S, J Environ Sci., 2007, 19(7), 874-878; DOI:10.1016/S1001-0742(07)60145-4

31. Liu W, Zhao W, Chen J B and Yang M M, Anal Chim Acta, 2007, 605, 41-45; DOI:10.1016/j.aca.2007.10.034

32. Gil R A, Salonia J A, Gásquez J A, Olivieri A C, Olsina R and Martinez L D, Microchem J., 2010, 95(2), 306-310; DOI:10.1016/j.microc.2010.01.005

33. Yao B and Yang L, Sep Sci Technol., 2008, 43(6), 1564-1580.

34. Prevot A B, Gulmini M, Zelano V and Pramauro E, Anal Chem., 2001, 73(15), 3790-3795; DOI:10.1021/ac010302z

35. Yao B and Yang L, Ind Eng Chem Res., 2008, 47(11), 3949-3956; DOI:10.1021/ie071618l

36. LI Hai-yan, The Research Centre of Environmental Science, Wuhan Institute of Science and Technology, Wuhan 430073, China.

37. Shokrollahi A, Abbaspour A, AzamiArdekani Z, Malekhosseini Z and Alizade A, Anal Methods, 2012, 4, 502; DOI:10.1039/C2AY05643G 